\title{
DESIGN AND SIMULATION OF PRINTED MICRO STRIP LOW PASS FILTER BASED ON THE ELECTROMAGNETIC MODELS 18GHZ PRINTED MICROSTRIP LOWPASS FILTER USING X-MODELS
}

\author{
Arfiya Kouser ${ }^{1}$, Pramod K B ${ }^{2}$, Kumaraswamy H.V ${ }^{3}$, Jayaraj $\mathbf{N}^{4}$ \\ ${ }^{I}$ Department of Electronics and Communication Engineering, The Oxford College of Engineering, Bangalore, Karnataka, \\ India \\ ${ }^{2}$ Department of Electronics Engineering, Jain University, Bangalore, Karnataka, India \\ ${ }^{3}$ Department of Telecommunication, R. V. College of Engineering, Bangalore, India \\ ${ }^{4}$ Department of Electronics and Communication Engineering, The Oxford College of Engineering, Bangalore, India
}

\begin{abstract}
This paper presents the Design, Simulation and characterization of Printed Micro strip Low Pass Filter based on 15 mil Alumina substrate. Simulations show a comparison between a pure EM simulation with EM Sight and a more efficient hybrid approach that combines EM analysis (using X-Models) with conventional circuit simulations and both approaches match the measured data. Furthermore, the proposed paper has four different low pass filter designs, lumped design; basic designs uses only micro strip lines; advanced design uses multiple edge coupled micro strip lines, EM sight design provides a very sharp cut-off frequency response with low insertion loss, results having great agreement with excellent correlation. Tuning and Optimization of the design is carried out using AWR Microwave office tool.
\end{abstract}

Keywords-EM sight, AWR, MMIC, X-Models, I-Filter

\section{INTRODUCTION}

A low-pass filter (LPF) offers easy passage to low-frequency signals and difficult passage to high-frequency signals. It is highly demanded in modern microwave communication systems, especially in wireless and mobile communications in order to suppress harmonics and spurious signals [1]. The amount of insertion loss and phase shift encountered by a signal passing through the filter and the amount of rejection of an undesired signal is a function of the filter design. Filters are networks that process signals in a frequency-dependent manner and they can be explained by examining the frequency dependent nature of the impedance of capacitors and inductors. With the advent of printed-circuit board (PCB) technology, microwave system also develop a strip line components and system with a technique of integrated circuit, called MMIC. It is a type of Integrated circuit device that operates at microwave frequencies $(300 \mathrm{MHz}-300 \mathrm{GHz})$. Inputs and outputs on MMIC devices are frequently matched to a characteristic impedance of 50 ohms. In advanced filter design, micro strip edge-coupled filters are used, they have advantages such as easy design procedures and simple integration into circuits. A general structure of parallel-coupled (or edge-coupled) micro strip filters that use half-wavelength line resonators. They are positioned so that adjacent resonators are parallel to each other along half of their length. This parallel arrangement gives relatively large coupling for a given spacing between resonators, therefore this filter structure is particularly convenient for constructing filters having a wider bandwidth as compared to the structure for the end coupled microstrip filters. For the creation of EM waves we need specific structures with time-varying charges and currents. At high frequencies hollow waveguides are used to transmit energy because they do not radiate at any frequency. There are new design methodologies for EM analysis such as topological partitioning, functional partitioning, and tuning methodology. In this filter design topological partitioning method is applied since it has advantage of gain in speed and also one can make certain changes very quickly.

This paper deals with the designing and fabrication of microstrip low pass filters. The designing is done using AWR Microwave Office simulation program developed by Applied Wave Research USA. This is a user-friendly software with all of the capabilities necessary for the accurate modelling and design of microwave components. It contains a linear, harmonic-balance, time domain, EM simulation, physical layout and includes linear and nonlinear noise analysis and can model nonlinear behavior existing in microwave devices.

\section{I-FILTER}

I-Filter is specifically developed for synthesis of lumped element and distributed filters, it brings useful filter synthesis to the integrated desktop. The module plugs directly into the 
Microwave Office design environment and is integrated as a wizard within the AWR Design Environment (AWRDE), it is completely integrated into AWRDE and easily accessible. Limits for minimum line width and minimum line spacing are specified in iFilter - which are typical dimensions for modern printed circuit board processes.

I-Filter also provides the ability to adjust secondary parameters in real time and see the results, in the case of hairpin filters, includes adjustment of the filter's nominal impedance. The short connecting lines between the resonators (in the U-turns), will have this impedance and the resonator lines will share this line width. If the area is assumed to be limited to $0.36 \times 0.30$ inches, the nominal impedance of the resonators can be adjusted to examine the effects of line width on performance and required area. Additionally, I-Filter performs accurate synthesis through electromagnetic verification with for instance, AWR's AXIEM 3D planar EM simulator. This is especially important when designing distributed filters.

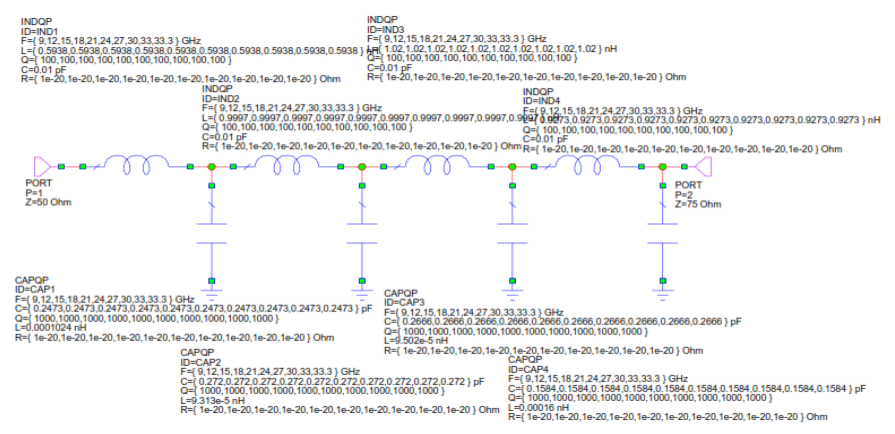

Fig 1: Schematic showing ifilter design

\subsection{Features:}

- $\quad$ Simplicity.

- $\quad$ Power - ideal or real, lumped or distributed, wide variety

- Ease-of-use.

- Integrated - works directly with AWR layout, EM, and optimization.

- Upgradeable - options for your design needs.

\section{MICROSTRIP}

Microstrip line consists of thin strip conductor suspended over ground plane by a low-loss dielectric material. Waves traveling in microstrip line not only travels in the dielectric medium they also travel in the air media above the microstrip line. Thus they don't support pure TEM waves, rather it supports quasi TEM approximation.

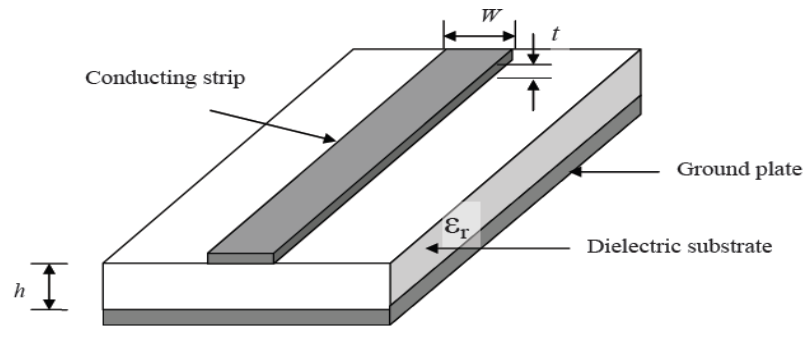

Fig 2: A basic Microstrip structure

The effective dielectric constant in terms of $\mathrm{W}$ (width of the Microstrip), $\mathrm{h}$ (height of the substrate) and $\varepsilon_{\mathrm{r}}$ (relative dielectric constant) given by Hammerstad and Jensen [11] is:

$$
\varepsilon_{\mathrm{re}}=\frac{\varepsilon_{\mathrm{r}}+1}{2}+\frac{\varepsilon_{\mathrm{r}}-1}{2}\left\{\frac{1}{\sqrt{1+\frac{12 \mathrm{~h}}{\mathrm{~W}}}}\right\}
$$

Characteristic impedance of the microstrip line is given by

$$
\mathrm{Z}_{\mathrm{c}}=\frac{1}{\mathrm{c} \sqrt{\mathrm{C}_{\mathrm{a}} \mathrm{C}_{\mathrm{d}}}}
$$

Where $\mathrm{c}$ is the velocity of electromagnetic waves in free space $c=2.99 \times 10^{8} \mathrm{~m} / \mathrm{s}$. The accuracy of $Z_{c} \sqrt{ } \varepsilon_{\text {re }}$ is better than $0.01 \%$.

\section{INITIAL LUMPED DESIGN:}

Insertion loss method is used in designing lumped element filter. It provides ways to shape pass band and stop band of the filter, although its design theory is much more complex. The order $N$ of a filter can be found as follows:

$$
N=\frac{\cosh ^{-1} \sqrt{\left(10^{0.1 \times I L}-1\right) /\left(10^{0.1 \times \alpha}-1\right)}}{\cosh ^{-1}\left(\omega / \omega_{c}\right)}
$$

The filter design specification has cut-off frequency of $18 \mathrm{GHz}$. From the above equation order of the filter is found to be 7 . For this design prototype parameters are as follows:

$\mathrm{g}_{0}=\mathrm{g}_{8}=1$
$\mathrm{~g}_{1}=\mathrm{g}_{7}=1.3722$
$\mathrm{~g}_{2}=\mathrm{g}_{6}=1.3781$
$\mathrm{~g}_{3}=\mathrm{g}_{5}=2.2756$
$\mathrm{~g}_{4}=1.5001$

\section{IMPLEMENTATION:}

\subsection{Basic Design:}

Basic filter is designed using microstrip lines such as MLIN, MLEF and MTEE\$ microstrips which are available in AWR tool. Input/Output ports are matched to 50ohms, these are also available in AWR tool. Microstrip has relative dielectric constant, $\varepsilon_{\mathrm{r}}=9.8$, substrate thickness $\mathrm{H}=15 \mathrm{mil}$, conductor 
thickness $\mathrm{T}=0.3 \mathrm{mil}$, metal bulk resistivity normalized to gold $\rho=2$ and loss tangent dielectric, Tand $=0.002$. Basic filter design has insertion-loss of $-1.0896 \mathrm{~dB}$ and return loss of $-42.441 \mathrm{~dB}$ at $18.95 \mathrm{GHz}$.

\section{FILTER BASIC SCHEMATIC}

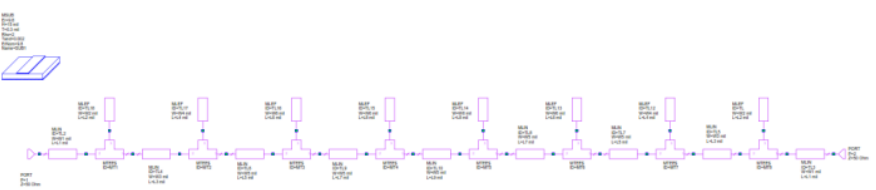

Fig 3: Basic schematic of LPF

\subsection{Advanced Filter Design:}

Advanced filter is designed using edge coupled microstrip line. The following figure shows the cross section of a coupled line. They support two modes of excitation, even and odd mode.

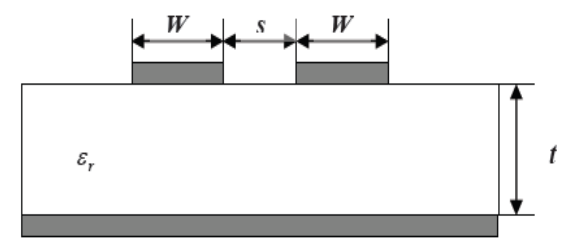

Fig 4: A Coupled Line Structure.

\subsection{Even Mode:}

In even mode excitation both the microstrip coupled lines have the same voltage potential resulting in a magnetic wall at the symmetry plane.

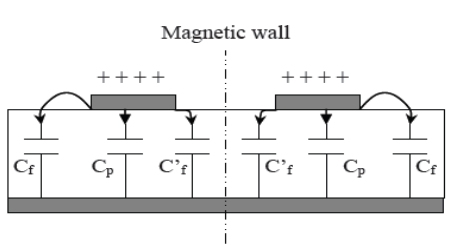

Fig 5: Quasi-TEM, Even Mode of a Pair of Coupled Microstrip Lines

The Odd mode Impedances can be calculated using the following formulae

$$
\left(Z_{o e}\right)_{j, j+1}=\frac{1}{Y_{0}}\left[1+\frac{J_{01}}{Y_{0}}+\left(\frac{J_{01}}{Y_{0}}\right)^{2}\right]
$$

Where,

$$
\frac{J_{01}}{Y_{0}}=\sqrt{\frac{\pi \Delta}{2 g_{0} g_{1}}}
$$

$$
\left.\frac{\mathrm{J}_{\mathrm{j} . \mathrm{j}+1}}{\mathrm{Y}_{0}}\right|_{\mathrm{j}=1 \text { to n-1 }}=\frac{\pi \Delta}{2 \omega_{1}^{\prime} \sqrt{2 g_{j} g_{j+1}}}
$$

$$
\frac{J_{n, n+1}}{Y_{0}}=\sqrt{\frac{\pi \Delta}{2 g_{n} g_{n+1}}}
$$

\subsection{Odd Mode}

In odd mode the coupled microstrip line possess opposite potential. This results into an electric wall at the symmetry. The following cross section diagram shows the same.

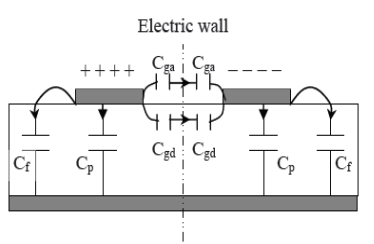

Fig 6: Quasi-TEM, Odd Mode of a Pair of Coupled Microstrip Lines

The Odd mode impedances can be calculated as same as Even mode impedances using the following formulae.

$$
\left(Z_{o o}\right)_{j, j+1}=\frac{1}{Y_{0}}\left[1-\frac{J_{01}}{Y_{0}}+\left(\frac{J_{01}}{Y_{0}}\right)^{2}\right]
$$

Where,

$$
\begin{gathered}
\frac{J_{01}}{Y_{0}}=\sqrt{\frac{\pi \Delta}{2 g_{0} g_{1}}} \\
\left.\frac{\mathrm{J}_{\mathrm{j} . \mathrm{j}+1}}{\mathrm{Y}_{0}}\right|_{\mathrm{j}=1 \text { to } \mathrm{n}-1}=\frac{\pi \Delta}{2 \omega_{1}^{\prime} \sqrt{2 g_{j} g_{j+1}}} \\
\frac{J_{n, n+1}}{Y_{0}}=\sqrt{\frac{\pi \Delta}{2 g_{n} g_{n+1}}}
\end{gathered}
$$

Table 1: Odd and Even Impedances values obtained from the admittance inverter parameters

\begin{tabular}{|l|l|l|l|}
\hline $\mathbf{J}$ & $\begin{array}{l}\text { Even - mode } \\
\text { impedance } \\
(\mathbf{Z o e})_{\mathbf{j}, \mathbf{j}+\mathbf{1}}\end{array}$ & $\begin{array}{l}\text { Odd - mode } \\
\text { impedance } \\
(\mathbf{Z o o})_{\mathbf{j}, \mathbf{j}+\mathbf{1}}\end{array}$ & $\begin{array}{l}\text { Characteristic } \\
\text { Impedance Zo } \\
\mathbf{Z o}^{\mathbf{2}} \approx(\mathbf{Z o e})(\mathbf{Z o o})\end{array}$ \\
\hline $\boldsymbol{O}$ & 78.777 & 37.9177 & 54.6514 \\
\hline $\mathbf{1}$ & 59.7244 & 43.0544 & 50.7089 \\
\hline $\mathbf{2}$ & 57.3072 & 44.3672 & 50.4238 \\
\hline $\mathbf{3}$ & 56.9688 & 44.5688 & 50.3888 \\
\hline
\end{tabular}


Applied Wave Research has developed accurate advanced numerical models for microstrip edge coupled lines, which are labelled MXCLIN elements. "X," which can range from 3 to 16, represents the number of parallel edge-coupled microstrip lines. Figure.7 shows AWR MXCLIN with 8 coupled lines.
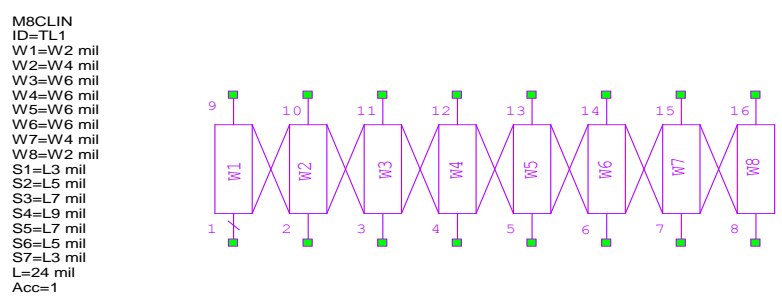

Fig 7: AWR MXCLIN advanced numerical element model where $\mathrm{X}=8$.

\subsection{Electromagnetic Model:}

At frequency greater than $3 \mathrm{GHz}$ it is compulsory for any microstrip design to undergo EM simulation. EM simulation considers all the dielectric effect so the response of the schematic will lose some of its characteristics and as the frequency goes higher and higher these responses may vary enormously. So at the higher frequency the EM Simulation is very necessary simultaneously it is difficulty to meet the specification. To increase the length of all resonators by connecting a multiple coupled line in between the two halves. The multiple coupled lines can come from a good circuit theory model, or it can be generated from an EM analysis. Increase the length of the added line to decrease the center frequency of the filter. To shorten all the resonators, connect a negative length line. While not physical, circuit theory and EM analysis programs both have no trouble doing this just connect a multiple coupled line in between the two halves. No need to repeat the entire EM analysis. Tune up your layout with circuit theory, do one more EM analysis to confirm the changes, and then fabricate. Design closure, quick and easy: a tunable EM analysis.

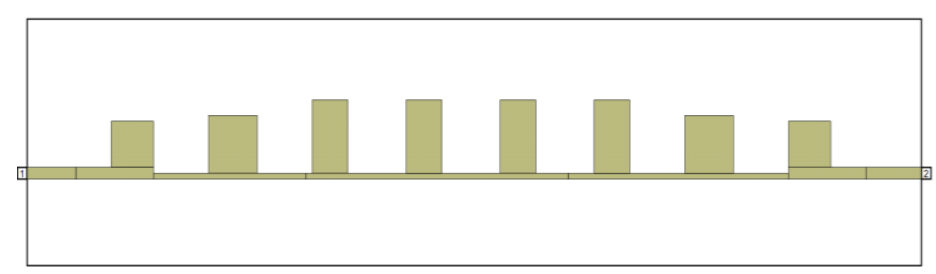

Fig 8: EM sight filter.

EM sight is designed using EM layer= 2, a perfect conductor material, drawing layer of top copper conductor, input port of impedance $50 \mathrm{ohms}$ and reference plane distance $=30 \mathrm{mil}$, and output port of impedance $50 \mathrm{ohms}$ and reference plane distance $=$ 34mil.

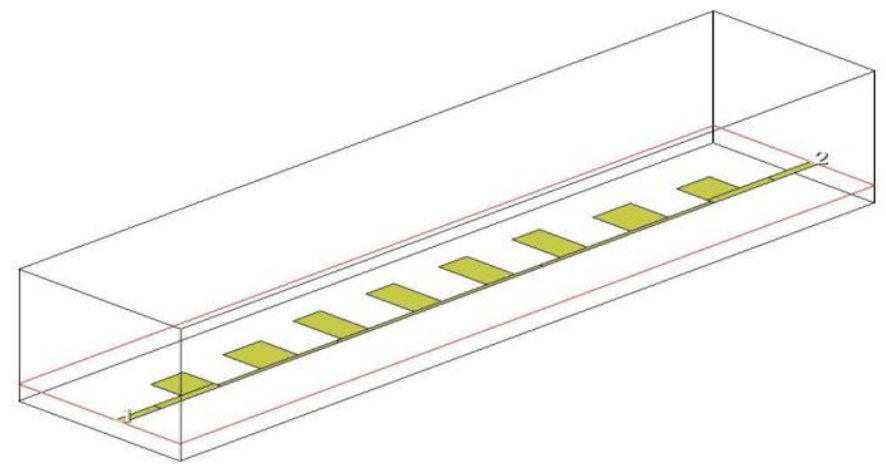

Fig 9: Three dimensional EM Structure design with enclosure box

An EM simulation is recommended to confirm the design accuracy fig 9 shows the simulation of planar 3D structures containing multiple metallization and dielectric layers. The structures can have interconnecting vias between layers or to ground. EMSight uses the Galerkin Method of Moments (MoM) in the spectral domain, an extremely accurate method for analyzing micro strip, this technique can provide accurate simulation results up to $100 \mathrm{GHz}$ and beyond.

\section{RESULT AND ANALYSIS:}

Insertion loss plot of lumped element low pass filter is shown in figure 10 . Here the insertion loss at $18.14 \mathrm{GHz}$ is $-2.999 \mathrm{~dB}$.

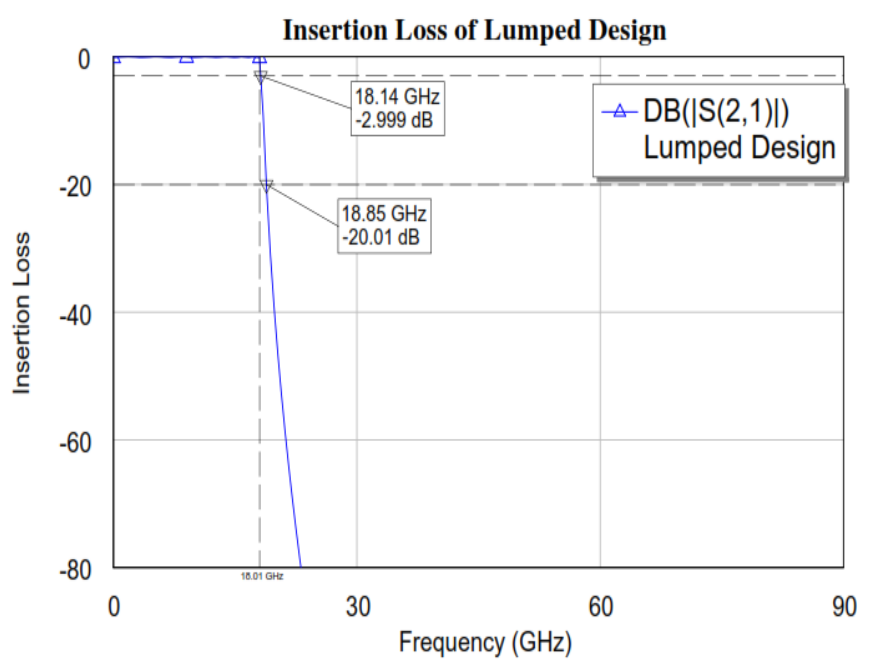

Fig 10: Insertion loss of Lumped design.

Return loss of lumped element low pass filter is shown in fig 11 . Here the return loss at $18.011 \mathrm{GHz}$ is $-16.029 \mathrm{~dB}$. 


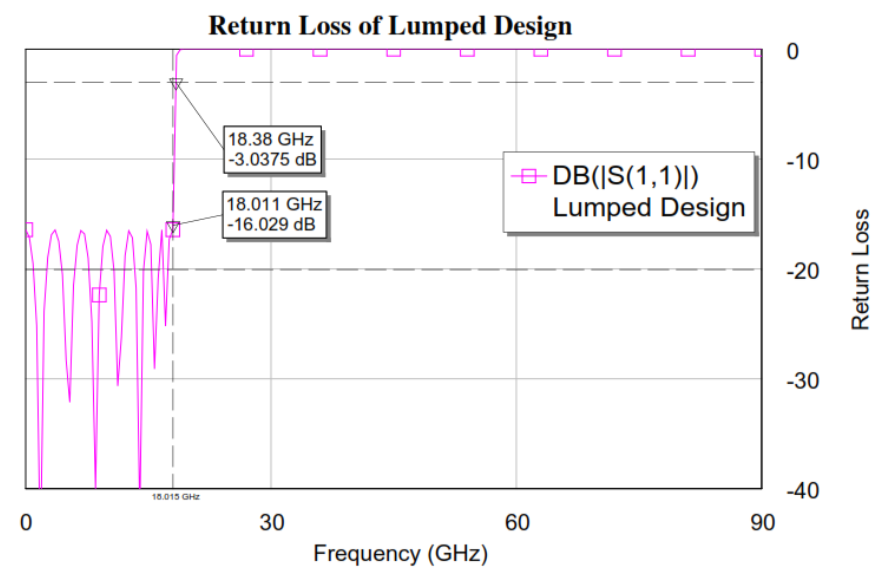

Fig 11: Return loss of Lumped design

Insertion loss of Basic low pass filter design is shown in fig 12. Here the insertion loss at $18.95 \mathrm{GHz}$ is $-1.0869 \mathrm{~dB}$.

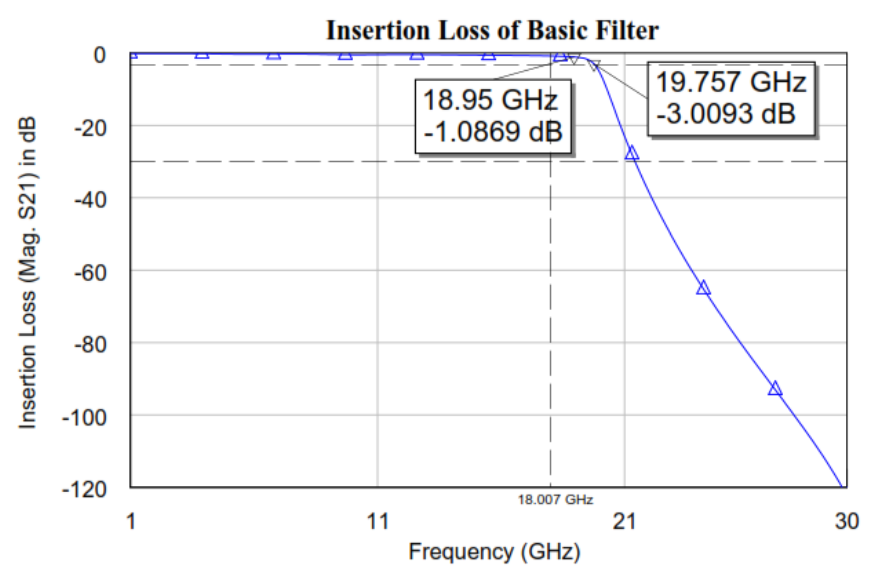

Fig 12: Insertion loss of Basic low pass filter.

Return loss of basic low pass filter is shown in fig 13. Here the return loss at $18 \mathrm{GHz}$ is $-42.441 \mathrm{~dB}$.

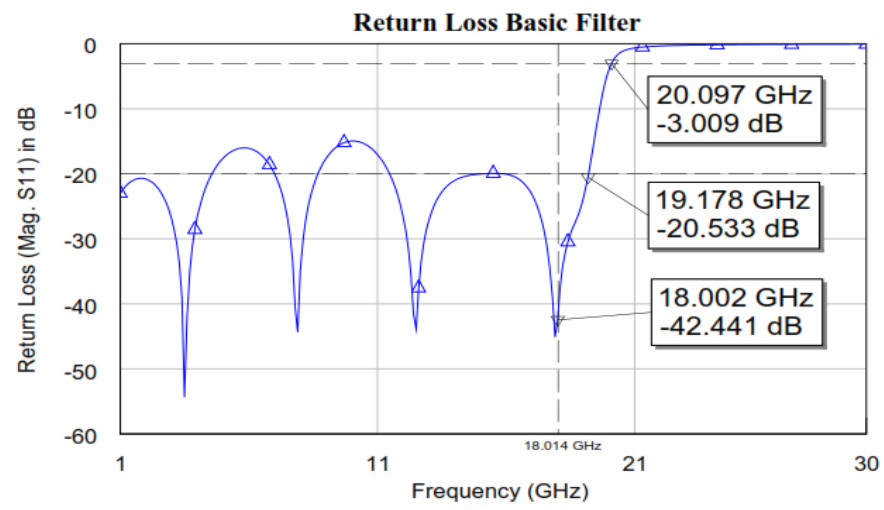

Fig 13: Return loss of basic low pass filter.
Insertion loss of advanced low pass filter is shown in fig 14 . Here the insertion loss at $18.498 \mathrm{GHz}$ is $-3.019 \mathrm{~dB}$.

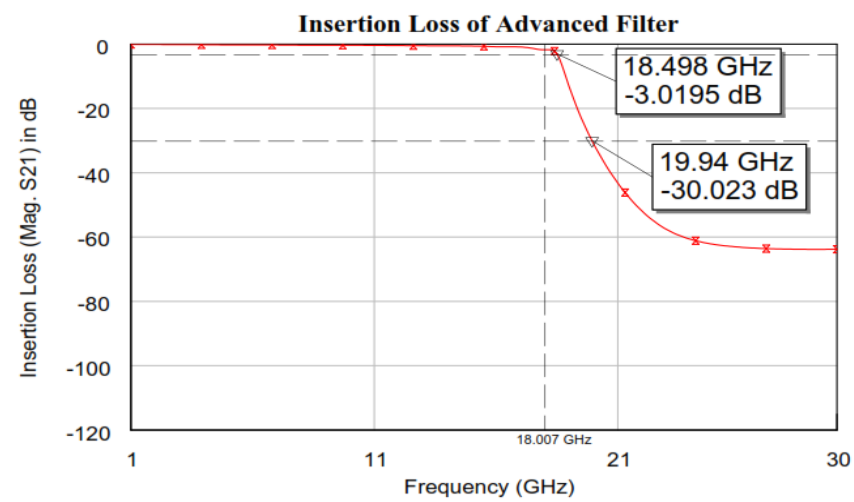

Fig 14: Insertion loss of advanced low pass filter.

Return loss of advanced low pass filter is shown in fig 15 . Here the return loss at $18 \mathrm{GHz}$ is $-10.001 \mathrm{~dB}$.

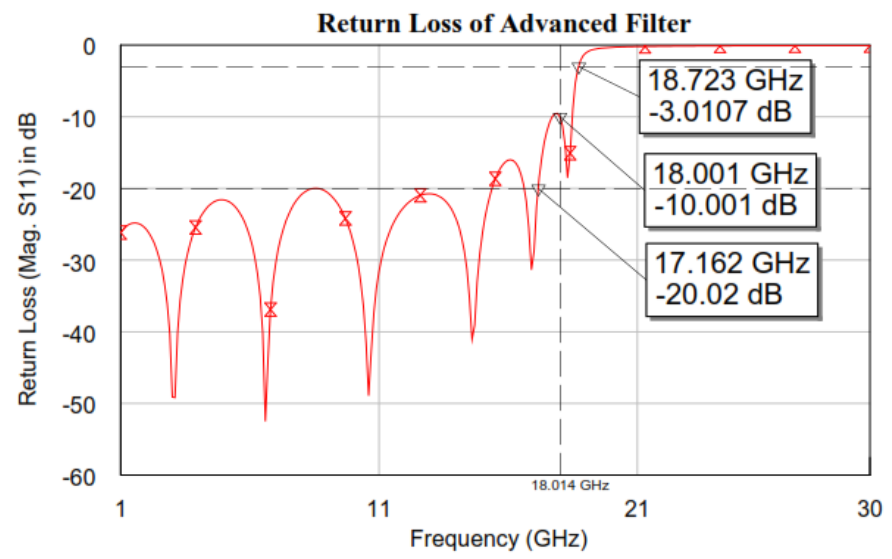

Fig 15: Return loss of advanced low pass filter.

Insertion loss of EM sight low pass filter is shown in fig 16 . Here the insertion loss at $18.586 \mathrm{GHz}$ is $-3.039 \mathrm{~dB}$.

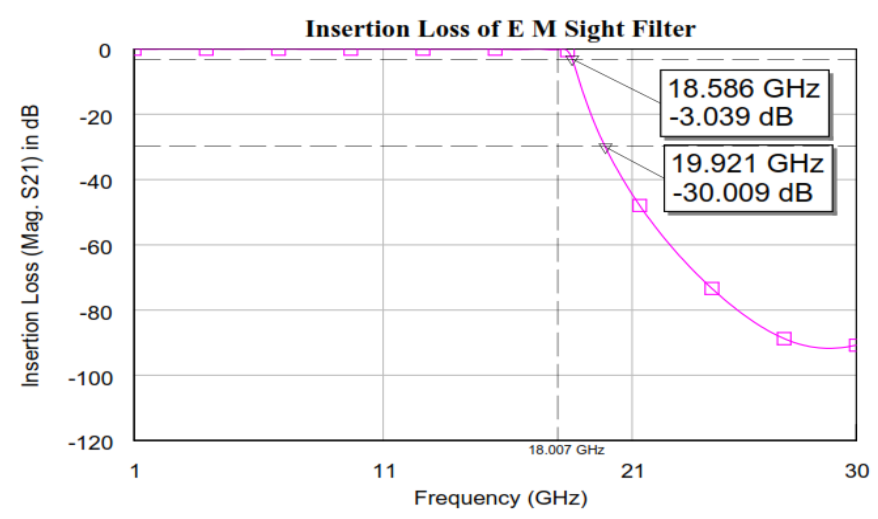

Fig 16: Insertion loss of EM sight low pass filter. 
Return loss of EM sight low pass filter is shown in fig 17. Here the return loss at $18.124 \mathrm{GHz}$ is $-20 \mathrm{~dB}$.

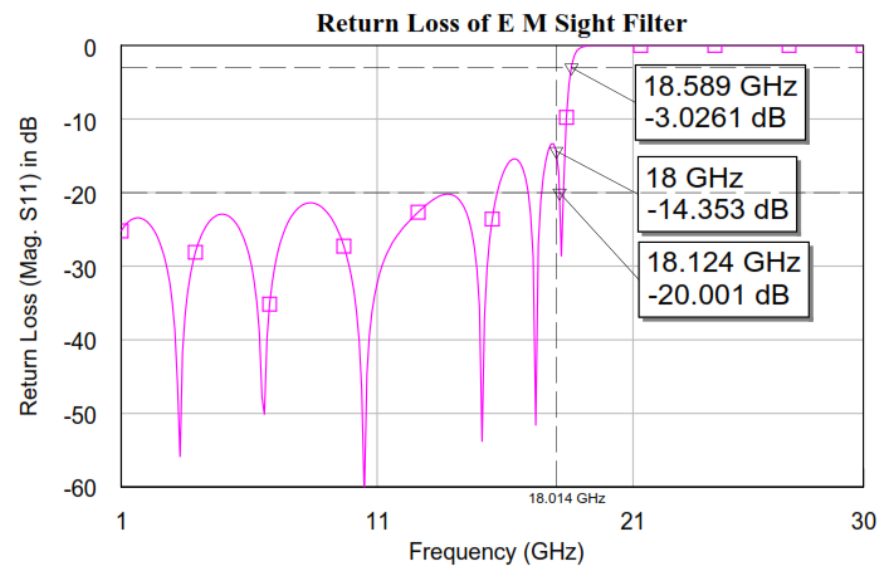

Fig 17: Return loss of EM sight low pass filter.

VSWR comparison between iFilter, basic LPF, advanced LPF and EM sight design is shown in fig 18. The advanced design and EM sight design having very good VSWR value. Variation of VSWR curve is crazy in Lumped design which is shown in fig 19.

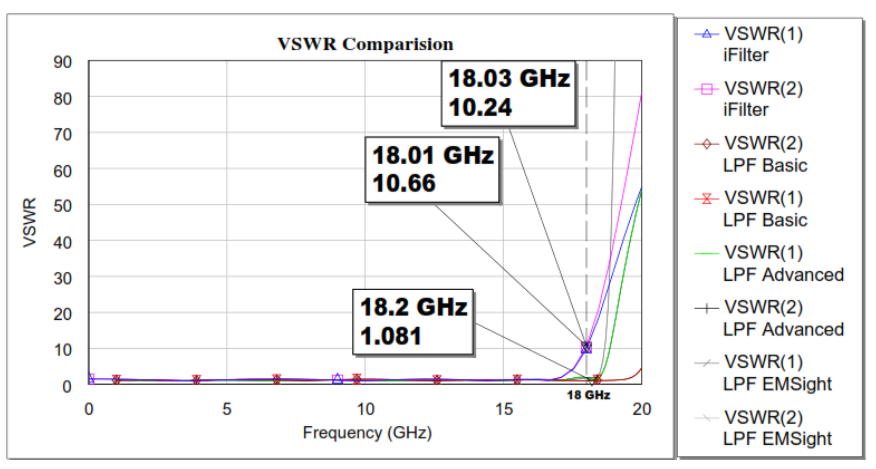

Fig 18: VSWR comparison.

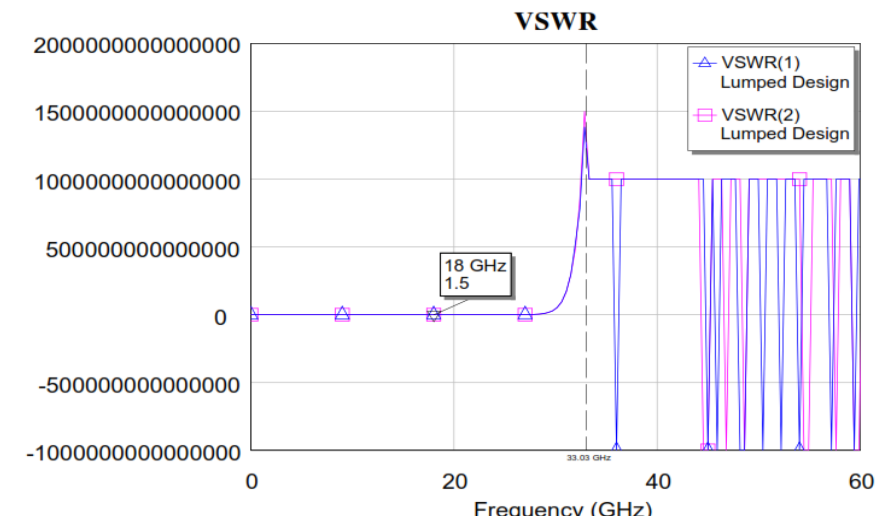

Fig 19: Variation of VSWR in lumped design.

\section{SUMMARY}

Table 2: Characteristics Comparison of all design types

\begin{tabular}{|c|c|c|c|c|}
\hline Design & $\begin{array}{l}\text { Frequen } \\
\text { cy }\end{array}$ & $\begin{array}{l}\text { Insertio } \\
\text { n loss }\end{array}$ & $\begin{array}{l}\text { Return } \\
\text { loss }\end{array}$ & $\begin{array}{l}\text { VSW } \\
\text { R }\end{array}$ \\
\hline $\begin{array}{l}\text { Lumped } \\
\text { design }\end{array}$ & $\begin{array}{l}18.14 \mathrm{GH} \\
\mathrm{z}\end{array}$ & $-2.996 \mathrm{~dB}$ & $\begin{array}{l}- \\
16.067 d \\
B\end{array}$ & 1.5 \\
\hline $\begin{array}{l}\text { Measured } \\
\text { filter }\end{array}$ & $\begin{array}{l}18.659 \mathrm{G} \\
\mathrm{Hz}\end{array}$ & $\begin{array}{l} \\
3.0573 d \\
\text { B } \\
\end{array}$ & $\begin{array}{l}- \\
18.458 \mathrm{~d} \\
\mathrm{~B}\end{array}$ & 10.24 \\
\hline Basic design & $\begin{array}{l}18.95 \mathrm{GH} \\
\mathrm{z}\end{array}$ & $\begin{array}{l}- \\
1.0869 \mathrm{~d} \\
\text { B }\end{array}$ & $\begin{array}{l}- \\
42.441 d \\
B\end{array}$ & 1.029 \\
\hline $\begin{array}{l}\text { Advanced } \\
\text { design }\end{array}$ & $\begin{array}{l}18.498 \mathrm{G} \\
\mathrm{Hz}\end{array}$ & $\begin{array}{l}- \\
3.0195 \mathrm{~d} \\
\text { B }\end{array}$ & $\begin{array}{l}- \\
10.001 d \\
B\end{array}$ & 1.826 \\
\hline $\begin{array}{l}\text { EM sight } \\
\text { design }\end{array}$ & $\begin{array}{l}18.586 \mathrm{G} \\
\mathrm{Hz}\end{array}$ & $-3.039 \mathrm{~dB}$ & $\begin{array}{l}- \\
20.001 d \\
B\end{array}$ & 1.081 \\
\hline
\end{tabular}

Table 3: Parameters Comparison with previous designs

\begin{tabular}{|c|c|c|c|c|}
\hline References & [2] & [7] & [10] & $\begin{array}{l}\text { This } \\
\text { work }\end{array}$ \\
\hline $\begin{array}{l}\text { Order of the } \\
\text { filter }\end{array}$ & 5 & 4 & 3 & 7 \\
\hline $\begin{array}{l}\text { Cut-off } \\
\text { frequency }\end{array}$ & $\begin{array}{l}2 \quad \& \\
3 \mathrm{GHz}\end{array}$ & $7.7 \mathrm{GHz}$ & $1990 \mathrm{MHz}$ & $18.95 \mathrm{GHz}$ \\
\hline $\begin{array}{l}\text { Insertion- } \\
\text { loss }\end{array}$ & $\begin{array}{l}-0.6 \mathrm{~dB} \\
\end{array}$ & $18 \mathrm{~dB}$ & $<0.6 \mathrm{~dB}$ & $1.0869 \mathrm{~dB}$ \\
\hline
\end{tabular}

\section{CONCLUSIONS}

This paper shows the design of $18 \mathrm{GHz}$ printed micro strip low pass filter on 15 mil Alumina substrate and simulation shows the comparison between lumped, basic, advanced and EM sight design successfully. The "LPF EMSight" shows the filter in the EMSight 2.5D electromagnetic simulator, which is viewed in three dimensions. This compares very closely to measured data. The "LPF Advanced" schematic makes use of advanced XModels (EM-based models), coupled lines and other linear schematic elements, including a substrate definition. This too gives excellent correlation. The "LPF Basic" indicates potential errors in schematic entry with the associated errors in results. A good comparison is achieved among all four designs and validated through circuits and EM sight in AWR MWO Environment, furthermore particular design can be chosen based on tradeoffs.

The design will be useful for Satellite and PTP Communications Links, Marine and Pleasure Craft Radar, Port Vessel Traffic Services etc... 


\section{REFERENCES}

[1] "A novel design of Narrowband Band pass filters onPTFE laminate using Radial stubs" Pramod, K.B. ; Shyam, S.S. ; Kumaraswamy, H.V. ;Praveen, K.B. Informatics, Electronics \& Vision (ICIEV), 2013 International Conference on Digital Object Identifier:10.1109/ICIEV.2013.6572584 Publication Year: 2013 , Page(s): 1 - 6

[2] "Design and Simulation of RF MEMS Switchable Low Pass Filter" M. Jeya Rani, M. Anitha, M. Arul Jothi and S. Kanthamani MEMS Design Center, Department of ECE, Thiagarajar College of Engineering, Madurai, Tamil Nadu ,INDIA. 978-1-4673-1515-9/12/\$31.00 (C)2012 IEEE

[3] "Design and Development of High Gain Wideband Microstrip Antenna and DGS Filters",by Adel Bedair Abdel-Mooty Abdel-Rahman, IEEE AP-S 2008

[4] "Design Of Compact Microstrip Low-Pass Filter With Ultra-Wide Stopband Using Sirs" L. Wang, H.C.Yang and Y.Li, School of Physical Electronics, UESTC Chengdu, China Vol. 18, 179-186, 2010

[5] "An $880 / 1760 \mathrm{MHz}$ Tunable Bandwidth Active RC Low-pass Filter using High Gain Amplifier" Kijin Kim, Electrical Engineering Department, KAIST 978-1-46732990-3/12/@2012 IEEE

[6] "A very linear low pass filter with automatic frequency tuning”, by J. Galán, M. Pedro, T. Sánchez-Rodríguez, F. Muñoz, R. G. Carvajal, and A. López-Martín IEEE TRANSACTIONS ON VERY LARGE SCALE INTEGRATION (VLSI) SYSTEMS, VOL. 21, NO. 1, JANUARY 2013

[7] "A DC to $6 \mathrm{GHz}$ Balanced Elliptic Low-Pass Filter in CMOS 130nm Technology", by Mohammad S. Mahani, Ramesh Abhari Electrical and Computer Engineering Department, McGill University, Montreal, Quebec, Canada 978-1-4577-1318-7/12/\$26.00 @ 2012 IEEE.

[8] " A Miniaturized High Out-band Suppression Low-pass Filter Based on the Lumped Circuit Model Using LTCC Technology", by Xiaoshi Huo and Peng Wang Research Institute of Electronic Science and Technology University of Electronic Science and Technology of China Chengdu China 978-1-4673-1697-2/12/\$31.00 () 2012 IEEE.

[9] John T. Taylor and Qiuting Huang. CRC handbook of electrical filters. CRC publisher, 1997.

[10] "Development of UWB HTS Bandpass Filters With Microstrip Stubs-Loaded Three-Mode Resonator", by Hiroyuki Ishii, Toru Kimura, Naotaka Kobayashi, Atsushi Saito, Zhewang Ma, and Shigetoshi Ohshima IEEE TRANSACTIONS ON APPLIED SUPERCONDUCTIVITY, VOL. 23, NO. 3, JUNE 2013 1051-8223/\$31.00 @ 2012 IEEE

[11] Cornelis Jan Kikkert, "A Design Technique for Microstrip Filters". Electrical and Computer Engineering James Cook University Townsville, Queensland, Australia.
[12] J. S. Hong and M. J. Lancaster, "Theory and experiment of novel microstrip slow-wave open-loop resonator filters," IEEE Trans. Microwave Theory Tech., vol. 45, pp. 2358-2365, 1997. 